\title{
Fronto-parietal coupling of brain rhythms in mild cognitive impairment: A multicentric EEG study
}

\author{
Claudio Babiloni ${ }^{\mathrm{a}, \mathrm{b}, \mathrm{c}, *}$, Raffaele Ferri $^{\mathrm{d}}$, Giuliano Binetti ${ }^{\mathrm{b}}$, Andrea Cassarino ${ }^{\mathrm{a}}$, Gloria Dal Forno ${ }^{\mathrm{e}}$, \\ Matilde Ercolani ${ }^{\mathrm{c}}$, Florinda Ferreri ${ }^{\mathrm{c}, \mathrm{e}}$, Giovanni B. Frisoni ${ }^{\mathrm{b}}$, Bartolo Lanuzza ${ }^{\mathrm{d}}$, Carlo Miniussi ${ }^{\mathrm{b}}$, \\ Flavio Nobili ${ }^{\mathrm{f}}$, Guido Rodriguez ${ }^{\mathrm{f}}$, Francesco Rundo ${ }^{\mathrm{d}}$, Cornelis J. Stam ${ }^{\mathrm{g}}$, Toshimitsu Musha ${ }^{\mathrm{h}}$, \\ Fabrizio Vecchio ${ }^{\text {a,c }}$, Paolo M. Rossini ${ }^{\text {b,c,e }}$ \\ a Dipartimento di Fisiologia Umana e Farmacologia, Università degli Studi di Roma “La Sapienza”, P.le Aldo Moro 5, 00185 Rome, Italy \\ b IRCCS “S. Giovanni di Dio-F.B.F.", Brescia, Italy \\ ${ }^{c}$ A.Fa.R. Osp. FBF, Isola Tiberina, Rome, Italy \\ ${ }^{\mathrm{d}}$ Department of Neurology, Oasi Institute for Research on Mental Retardation and Brain Aging (IRCCS), Troina, Italy \\ e University "Campus Biomedico", Rome, Italy \\ ${ }^{\mathrm{f}}$ Division of Clinical Neurophysiology (DIMI), University of Genova, Italy \\ ${ }^{g}$ Department of Clinical Neurophysiology, VU University Medical Centre, Amsterdam, The Netherlands \\ h Toshimitsu Musha, Brain Functions Laboratory, Inc. Tokyo, Japan
}

Received 22 August 2005; received in revised form 21 October 2005; accepted 24 October 2005

Available online 21 November 2005

\begin{abstract}
Electroencephalographic (EEG) data were recorded in 69 normal elderly (Nold), 88 mild cognitive impairment (MCI), and 109 mild Alzheimer's disease (AD) subjects at rest condition, to test whether the fronto-parietal coupling of EEG rhythms is in line with the hypothesis that MCI can be considered as a pre-clinical stage of the disease at group level. Functional coupling was estimated by synchronization likelihood of Laplaciantransformed EEG data at electrode pairs, which accounts for linear and non-linear components of that coupling. Cortical rhythms of interest were delta $(2-4 \mathrm{~Hz})$, theta $(4-8 \mathrm{~Hz})$, alpha $1(8-10.5 \mathrm{~Hz})$, alpha $2(10.5-13 \mathrm{~Hz})$, beta $1(13-20 \mathrm{~Hz})$, beta $2(20-30 \mathrm{~Hz})$, and gamma $(30-40 \mathrm{~Hz})$. Compared to the Nold subjects, the AD patients presented a marked reduction of the synchronization likelihood (delta to gamma) at both fronto-parietal and inter-hemispherical (delta to beta 2) electrodes. As a main result, alpha 1 synchronization likelihood progressively decreased across Nold, MCI, and mild AD subjects at midline (Fz-Pz) and right (F4-P4) fronto-parietal electrodes. The same was true for the delta synchronization likelihood at right fronto-parietal electrodes (F4-P4). For these EEG bands, the synchronization likelihood correlated with global cognitive status as measured by the Mini Mental State Evaluation. The present results suggest that at group level, fronto-parietal coupling of the delta and alpha rhythms progressively becomes abnormal though MCI and mild AD. Future longitudinal research should evaluate whether the present EEG approach is able to predict the cognitive decline in individual MCI subjects.
\end{abstract}

(C) 2005 Elsevier Inc. All rights reserved.

Keywords: Mild Alzheimer's disease (mild AD); Mild cognitive impairment (MCI); Electroencephalography (EEG); Synchronization of brain rhythms; Synchronization likelihood

\section{Introduction}

Holy Grail of research on pathological aging is the early detection of Alzheimer's disease (AD) at pre-clinical stage,

\footnotetext{
* Corresponding author. Tel.: +3906 49910989; fax: +3906 49910917.

E-mail address: claudio.babiloni@uniroma1.it (C. Babiloni).

URL: http://hreeg.ifu.uniroma1.it/.
}

when the cognitive deficits are barely detectable [15,95,102]. Accordingly, mild cognitive impairment (MCI) is characterized by selective memory impairment insufficient to meet criteria for a diagnosis of dementia $[34,81,82]$. This condition is considered as a prodromic stage of $\mathrm{AD}[2,11,41,42,81,97]$. Annual conversion rate from normality to $\mathrm{AD}$ is estimated at about $0.2-4 \%$ [36,81], whereas that from $\mathrm{MCI}$ to $\mathrm{AD}$ is about $6-25 \%$ [81,83]. These data suggest that, in several (yet not all) cases, MCI is a transition state on a linear progression towards $\mathrm{AD}$. 
Previous studies have investigated the electrophysiological substrate of AD. In mild AD, electroencephalographic (EEG) rhythms differ from normal elderly (Nold) and vascular dementia subjects, AD patients being characterized by higher delta $(0-4 \mathrm{~Hz})$ and lower posterior alpha $(8-13 \mathrm{~Hz}[7,28,29,45,88])$. Abnormality of the EEG rhythms in dementia has been associated with altered regional cerebral blood flow (rCBF)/metabolism and cognitive function, as assessed by the Mini Mental State Examination (MMSE) [25,47,51,52,74,75,80,90,92,93,100,101,109]. Similarly, MCI subjects have shown an increase of theta $(4-7 \mathrm{~Hz})$ power [43,50,119] as well as decrease of alpha power [40,43-45,50,119], when compared to Nold subjects. These EEG parameters have presented an intermediate magnitude in MCI subjects with respect to those observed in normal subjects and dementia patients $[32,45,48]$.

Despite the converging evidence of abnormal cortical rhythms in MCI and AD, EEG power analysis alone is unable to predict conversion from MCI to dementia. It is reasonable that additional biological parameters are needed for this purpose. In this regard, several studies have shown that AD is also characterized by an abnormal linear coupling of EEG rhythms between cortical regions, as revealed by spectral coherence $[1,49,59,67,79,113,114]$. Indeed, EEG coherence represents the covariance of the spectral activity at two electrode locations and can be considered as a rough measure of the temporal synchronicity of coupled neural populations. In that sense, it roughly reflects functional cortical coupling or connectivity. This is of interest since functional cortical coupling is modulated by cholinergic systems [116] and AD is characterized by a disruption of basal forebrain cholinergic inputs to cortex and hippocampus [69]. Thus, a decrease of cortical EEG coherence may be a fine marker of AD.

Most of the EEG studies in AD patients have reported a prominent decrease of EEG-MEG coherence at the alpha band $[1,12,13,48,49,59,64,65,67,79,113,114]$. The reduction of alpha coherence in AD patients has been also found to be associated with ApoE genetics risk of dementia, which is supposed to be mediated by cholinergic deficit [49]. Instead, coherence at the delta and theta bands has been less straightforward. Some studies have shown a decrement of slow EEG coherence in AD patients $[1,23,30,64]$, whereas others have reported its increase [20,67].

It should be remarked that EEG spectral coherence is able to disclose just the linear interactions between pairs of cerebral oscillators, which are reflected by a coupling of synchronous EEG oscillations. This is clearly a limitation when the functional connectivity between two areas is investigated at large. To account for both linear and non-linear coupling (i.e. coupling of asynchronous oscillations) of cortical rhythms, several new methods have been proposed from the theory of non-linear dynamical systems $[3,66,98,99]$. One of the most promising methods is the so-called synchronization likelihood, which combines sensitivity to linear and non-linear functional coupling of EEG rhythms with a high time resolution [103]. Global synchronization likelihood of resting EEG data (each channel versus all others) has been shown to be significantly decreased at $10-12,14-18$, and $18-22 \mathrm{~Hz}$ bands in AD patients, when compared to MCI and/or Nold subjects $[85,105]$. When applied to magnetoencephalographic data [104], global synchronization likelihood was found to be lower in mild AD compared to Nold subjects at upper alpha $(10-14 \mathrm{~Hz})$, upper beta $(18-22 \mathrm{~Hz})$, and gamma $(22-40 \mathrm{~Hz})$ bands.

Recently, synchronization likelihood has been computed in aged subjects taking into account the topographical features of EEG functional coupling [10]. It has been shown that frontoparietal synchronization likelihood of EEG alpha rhythm distinguished AD patients from Nold and vascular dementia subjects [10]. Keeping in mind the results of the mentioned study, the present investigation tested whether the fronto-parietal coupling of the alpha rhythms progressively decreases across Nold, MCI, and mild AD subjects. The hypothesis is that at group level, such a fronto-parietal (rather than inter-hemispherical) EEG coupling is sensitive to the pre-clinical stage of the disease in MCI subjects.

\section{Methods}

\subsection{Subjects}

For the present multicentric EEG study, 109 mild AD patients, $88 \mathrm{MCI}$ patients, and 69 Nold subjects were recruited in the framework of several local projects on biologic correlates of pathological aging. The multicentric nature of the study allowed a relatively fast recruitment of the experimental subjects over a large territory, an important aspect for the generalization of the results. All clinical units provided a balanced number of subjects for the three mentioned groups. Local institutional ethics committees approved the study. Informed consent was obtained from all participants or their caregivers, according to the Code of Ethics of the World Medical Association (Declaration of Helsinki) and standards established by the Authors' Institutional Review Boards. The recruitment of the subjects was not "consecutive", since the aim of the study focused on subjects having certain age features, global cognitive status, and the availability of artifact free EEG data. Most of the MCI and AD subjects were evaluated during the course of the diagnostic phase.

\subsection{Diagnostic criteria}

Probable AD was diagnosed according to NINCDS-ADRDA [68] and DSM IV criteria. All recruited AD patients underwent general medical, neurological and psychiatric assessments. Patients were also rated with a number of standardized diagnostic and severity instruments that included the Mini Mental State Examination [35], the Clinical Dementia Rating Scale (CDR [46]), the 15-item version of the Geriatric Depression Scale (GDS [118]), the Hachinski Ischemic Scale (HIS [96]), and the Instrumental Activities of Daily Living scale (IADL [62]). Neuroimaging diagnostic procedures (CT or MRI) and complete laboratory analyses were carried out to exclude other causes of progressive or reversible dementias, in order to have a homogenous AD patient sample. Exclusion criteria included, in particular, evidence of (i) frontotemporal dementia, (ii) vascular dementia based on clinical and radiological grounds, (iii) extrapyramidal syndromes, (iv) reversible dementias (including dementia of depression), and (v) fluctuations in cognitive performance and visual hallucinations (suggestive of a possible Lewy body dementia).

Inclusion and exclusion criteria for MCI diagnosis aimed at selecting elderly persons with objective cognitive deficits, especially in the memory domain, who did not meet criteria for dementia or AD [81]. Inclusion criteria for MCI subjects were: (i) objective memory impairment on neuropsychological evaluation, as defined by performances $\geq 1.5$ standard deviation below the mean value of age and education-matched controls for a test battery including Busckhe-fuld and 
Table 1

Mean values ( \pm standard error) of the demographic and clinical characteristics of the study subjects (i.e. 75 mild AD, $88 \mathrm{MCI}$, and 79 Nold subjects)

\begin{tabular}{llll}
\hline & Nold & Ad & MCI \\
\hline Subject & 69 & 109 & 88 \\
MMSE & $28.8 \pm 0.1$ & $22 \pm 0.2$ & $25.8 \pm 0.2$ \\
Age & $71 \pm 0.7$ & $77.7 \pm 0.7$ & $73.1 \pm 0.7$ \\
Education & $9.2 \pm 0.4$ & $6.6 \pm 0.4$ & $7.6 \pm 0.4$ \\
Female/male & $45 \mathrm{~F} / 24 \mathrm{M}$ & $80 \mathrm{~F} / 29 \mathrm{M}$ & $51 \mathrm{~F} / 37 \mathrm{M}$ \\
\hline
\end{tabular}

memory Rey tests; (ii) normal activities of daily living as documented by history and evidence of independent living; and (iii) a clinical dementia rating score of 0.5 . Exclusion criteria for MCI were: (i) $\mathrm{AD}$, as diagnosed by the procedures described above; (ii) evidence of concomitant dementia such as frontotemporal, vascular dementia, reversible dementias (including dementia of depression), fluctuations in cognitive performance, and/or features of mixed dementias; (iii) evidence of concomitant extrapyramidal symptoms; (iv) clinical and indirect evidence of depression as revealed by GDS scores greater than 14; (v) other psychiatric diseases, epilepsy, drug addiction, alcohol dependence, and use of psychoactive drugs or drugs interfering with brain cognitive functions including acetylcholinesterase inhibitors; and (vi) current or previous systemic diseases (including diabetes mellitus) or traumatic brain injuries.

Nold subjects were recruited mainly among patients' spouses. All Nold subjects underwent physical and neurological examinations as well as cognitive screening (including MMSE). Subjects affected by chronic systemic illnesses (i.e. diabetes mellitus or organ failure) were excluded, as were subjects receiving psychoactive drugs. Subjects with a history of present or previous neurological or psychiatric disease were also excluded. All Nold subjects had a GDS score lower than 14.

Table 1 reports the mean values and standard error of relevant personal and clinical parameters of mild AD, MCI, and Nold subjects. As expected, women were overrepresented in the $\mathrm{AD}$ group. As there is no previous evidence of gender-specific effects on EEG rhythms, it was felt that this would not interfere with the results. Among these variables, age and education were used as covariates in the statistical evaluation of cortical sources of EEG rhythms, to remove possible confounding effects. Of note, the results showed in Section 3 were confirmed by a control analysis in which data referred to subsets of the three groups fully matched for age.

\subsection{EEG recordings}

EEG data were recorded in resting subjects (eyes-closed) by specialized clinical units. All EEG recordings were performed $(0.3-70 \mathrm{~Hz}$ bandpass) from 19 electrodes positioned according to the International 10-20 System (i.e. Fp1, Fp2, F7, F3, Fz, F4, F8, T3, C3, Cz, C4, T4, T5, P3, Pz, P4, T6, O1, O2). A specific reference electrode was not imposed to all recording units of this multicentric study, since data were made reference-free by Laplacian transformation of the EEG activity. To monitor eye movements, the electrooculogram $(0.3-70 \mathrm{~Hz}$ bandpass) was also collected. All data were digitized in continuous recording mode ( $5 \mathrm{~min}$ of EEG; up to $256 \mathrm{~Hz}$ sampling rate). In all subjects, EEG recordings were performed in the late morning. State of vigilance was controlled by visual inspection of EEG traces during recording session and subjects' drowsiness was avoided by verbal warnings. At the time of EEG recording, no patient received medications that could influence EEG rhythms such as benzodiazepines. Of note, EEG recordings lasting $5 \mathrm{~min}$ allowed the comparison of the present results with several previous AD studies using either EEG recording periods shorter than $5 \mathrm{~min}[7,10,21,73,89,94,109]$ or shorter than $1 \mathrm{~min}[28,29]$. Longer resting EEG recordings in $\mathrm{AD}$ patients would have reduced data variability but would have increased the possibility of EEG rhythmic oscillations slowing because of reduced vigilance and arousal.

The EEG epochs with ocular, muscular and other types of artifacts were preliminary identified by a computerized automatic procedure [72]. Two expert electroencephalographers double-checked and confirmed visually the automatic selections. They were blind to the diagnosis of the subjects. The EEG epochs contaminated by artifacts were removed.

\subsection{Surface Laplacian estimation}

Artifact-free EEG data were spatially enhanced by surface Laplacian estimation (regularized 3-D spline function), which reduces the head volume conduction effects and has been found to be useful in detecting linear and non-linear dynamics $[5,8,76,108]$. The single trial analysis was carefully repeated on the Laplacian-transformed EEG data, to discard the single trials contaminated by residual computational artifacts.

The results of the aforementioned study [10] encouraged the Laplaciantransformation of the EEG data before the analysis of the synchronization likelihood in aged subjects. However, it should be remarked that the surface Laplacian estimates should always be interpreted with caution. First, the surface Laplacian maxima might not always overlie the cortical sources of EEG potentials, due to the influence of both radial and tangential cortical generators [5]. This limitation might be less important here, since radial cortical sources are supposed to prevail in the generation of EEG rhythmicity. Second, the surface Laplacian estimate might be not fully reliable when computed at the border electrodes [31]. For this reason, we did not consider temporal electrodes in the final data analysis. Third, the "low" resolution of our EEG spatial sampling (19 recording channels) only permitted the evaluation of large regions of interest such as frontal, central, and parietal areas of both hemispheres. Such a coarse level of anatomical description took well into account the slight changes in brain volume provoked by atrophy processes occurring at early $\mathrm{AD}$ stages.

Another important methodological issue is the influence of the spline Laplacian estimators on the computation of the functional coupling with synchronization likelihood. In this regard, recent investigations have shown that artifactual effects are negligible in the following conditions: correct implementation of spline Laplacian functions [78], calculation of coherence at scalp electrodes more than 3 or $4 \mathrm{~cm}$ apart, and exclusion of border electrodes [77,78]. Here, we strictly followed these guidelines $[4,5,8,9]$

\subsection{Synchronization likelihood}

Synchronization likelihood is a measure of the dynamical interdependencies between a time series (EEG channel) and one or more other time series [103]. In contrast to EEG spectral coherence probing the linear interactions between two cerebral areas (i.e. coupling of synchronous oscillations), synchronization likelihood measures linear as well as non-linear (i.e. coupling of asynchronous oscillations) interdependencies. It can do so as a function of time, making it suitable for non-stationary time series. A detailed technical description of synchronization likelihood can be found in the paper by Stam and van Dijk [103]. Briefly, we consider two dynamical systems, $X$ and $Y$. These systems can be thought of as neural networks underlying the EEG recorded at two different electrode positions. In this framework, the dynamics of $X$ and $Y$ can be represented by vectors $X_{i}$ and $Y_{j}$ in their respective state spaces; such state space vectors can be obtained from the time series by time-delay embedding [110]. In the EEG framework, the concept of "state of the system" is practically expressed in terms of the level of neural synchronization of the neural networks underlying the potentials recorded at two electrode positions. Such a level neural synchronization would be expressed by the amplitude of the EEG voltage. We can now define "synchronization" as the likelihood that the state of one system is a function $F$ of the state of the other system: $X=F(Y)$. Function $F$ does not need to be linear; only requirement is that it is locally smooth. This concept can be put in practice by synchronization likelihood, which is simply the chance that, if system $X$ is in the same state at two different times $i$ and $j$, then system $Y$ will also be in the same state at time $i$ and $j$. The condition of "being in the same state" is operationalized by computing distances between vectors $X_{i}$ and $X_{j}$. If this distance is smaller than a small critical distance $r_{\text {cutoff }}, X$ is in the same state at time $i$ and $j$. In case of complete synchronization, synchronization likelihood $=1$; in case of independent systems, synchronization likelihood equals the chance that two random vectors of $Y$ will be closer than $r_{\text {cutoff. }}$. To this purpose, $r_{\text {cutoff }}$ is chosen separately for $X$ and $Y$, so that the likelihood of random vectors are close and can be fixed at a known low value called $p_{\text {ref }}$ (usually chosen to be 0.05). When two systems $X$ and $Y$ have independent dynamics, synchronization likelihood $=p_{\text {ref }}$. For the state space reconstruction, an embedding dimension of 10 was used with a vector data lag of 10. Finally, in order to avoid the effects of a potential correlation between adjacent data points, Theiler 
correction was introduced with a value of 100 data points [112]; the value of $p_{\text {ref }}$ was 0.01 .

It should be remarked that there are no established criteria for the fine tuning of the parameters for the computation of the synchronization likelihood. With respect to our previous study [10], the availability of more powerful computers allowed us to enhance the accuracy of the measurement of synchronization likelihood at the expense of the computation time. This was possible by means of slightly different parameters, which have been successfully utilized in a very recent study on EEG synchronization in AD patients [106]. From a quantitative point of view, they slightly deflate the values of the synchronization likelihood, when compared to the values obtained with the parameters we used previously [10].

For the computation of the synchronization likelihood, we used artifact-free $16 \mathrm{~s}$ epochs (sample frequency $256 \mathrm{~Hz} ; 4096$ samples) of Laplacian-transformed EEG data. These data were preliminary bandpass filtered (digital off-line filter with no phase-shift), in order to analyze separately the synchronization likelihood in the following frequency bands: delta $(2-4 \mathrm{~Hz})$, theta $(4-8 \mathrm{~Hz})$, alpha 1 $(8-10.5 \mathrm{~Hz})$, alpha $2(10.5-13 \mathrm{~Hz})$, beta $1(13-20 \mathrm{~Hz})$, beta $2(20-30 \mathrm{~Hz})$, and gamma $(30-40 \mathrm{~Hz})$. These band frequencies were chosen averaging those used in previous relevant EEG studies on dementia [14,27,50,63,91]. Of note, the synchronization likelihood method models both non-linear and linear functional coupling between two time series and it has been applied to data filtered (narrow band) with linear approaches such as FFT [103]. The preliminary bandpass filtering of the data is a useful procedure to model the functional coupling at frequency bands of physiological interest. In particular, this procedure allows the detection of changes in the functional coupling even when limited to a single narrow band. On the other hand, the preliminary linear filtering might affects the balance of the non-linear and linear components of functional coupling as revealed by the synchronization likelihood. This issue should be taken into account in studies aimed at dissociating the linear from the non-linear aspects of coupling. Details on space reconstruction, embedding dimension, and Theiler correction were reported elsewhere [103].

Computation of the individual alpha frequency has previously provided useful information in the evaluation of different kinds of dementia [71]. In that study, it has been shown that the slowing of the alpha frequency peak in vascular dementia and mild AD does not overcome, on average, the limit of $8 \mathrm{~Hz}$. Therefore, the alpha 1 band here included the alpha frequency peak of the vast majority of all subjects considered. Finally, the use of standard frequency bands allowed a full comparison with the reference EEG study computing synchronization likelihood in subjects with $\mathrm{AD}$ and vascular dementia [10].

Here, the synchronization likelihood was computed from pairs of electrodes for the evaluation of fronto-parietal functional coupling (intra-hemispheric) and callosal functional coupling (inter-hemispheric). The Fronto-parietal electrode pairs of interest were $\mathrm{F} 3-\mathrm{P} 3, \mathrm{Fz}-\mathrm{Pz}$, and F4-P4, while the inter-hemispheric electrode pairs of interest were F3-F4, C3-C4, and P3-P4 (Fig. 1).

\subsection{Statistical analysis of synchronization likelihood}

The synchronization likelihood values (dependent variable) were compared by means of ANOVA analysis. The Mauchley's test evaluated the sphericity assumption. Correction of the degrees of freedom was made with the Greenhouse-Geisser procedure. The Duncan test was used for post hoc comparisons $(p<0.05)$.

A first ANOVA used the factors Subject (mild AD, MCI, Nold), Band (delta, theta, alpha 1, alpha 2, beta 1, beta 2, gamma), and Fronto-parietal electrode pair (F3-P3, Fz-Pz, F4-P4). Compared to it, the second ANOVA analysis used the factor Inter-hemispheric electrode pair (F3-F4, C3-C4, P3-P4) instead of the fronto-parietal one. In agreement with the working hypothesis, post hoc testing looked for synchronization likelihood values according to the pattern Nold $>$ MCI $>$ mild AD or Nold $<$ MCI $<$ mild AD $(p<0.05)$.

Statistically significant values of the synchronization likelihood were evaluated as type (linear and/or non-linear) of correlation with the MMSE score in all subjects as a whole group (Pearson test; Bonferroni corrected, $p<0.05$ ). The linear correlation was computed with the $r^{2}$ values of the Pearson test (Bonferroni corrected, $p<0.05$ ). The non-linear correlations were computed evaluating the coefficient of determination $r^{2}$ for exponential, logarithmic, and power functions. These $r^{2}$ values were computed with the following mathematical formula:

$r^{2}=1-\left(\frac{\mathrm{SSE}}{\mathrm{SST}}\right)$

where

$$
\mathrm{SSE}=\Sigma\left(\mathrm{y}_{\mathrm{i}}-\mathrm{y}_{\mathrm{i}}\right) \text { and } \mathrm{SST}=\left(\Sigma \mathrm{y}_{\mathrm{i}}{ }^{2}\right)-\left(\left(\Sigma \mathrm{y}_{\mathrm{i}}\right)^{2} / \mathrm{n}\right)
$$

where $n$ is the number of samples (i.e. subjects), $y_{i}$ the real value, and $y$ is the approximated value calculated with the following formula:

$$
\begin{gathered}
\#_{\mathrm{i}}=\mathrm{c} \ln \mathrm{x}_{\mathrm{i}}+\mathrm{b} \text { for logarithmic functions ( } \mathrm{c}, \mathrm{b} \text { constant) } \\
¥_{\mathrm{i}}=\mathrm{c} \mathrm{e}^{\mathrm{bx}}{ }_{\mathrm{i}} \text { for exponential functions ( } \mathrm{c}, \mathrm{b} \text { constant) } \\
\left.\#_{\mathrm{i}}=\mathrm{c} \mathrm{x}_{\mathrm{i}}^{\mathrm{b}} \text { for power functions ( } \mathrm{c}, \mathrm{b} \text { constant }\right)
\end{gathered}
$$

Finally, $r^{2}$ of the non-linear simple functions was compared with $r^{2}$ of the linear function, to evaluate the prevalence of linear or non-linear EEG correlations between values of the synchronization likelihood and MMSE.

\section{Results}

Fig. 2 illustrates means of the synchronization likelihood computed in Nold, MCI, and mild AD subjects from frontoparietal (top of the figure: F3-P3, Fz-Pz, F4-P4) and inter-

\section{0-20 SYSTEM (19 ELECTRODES)}

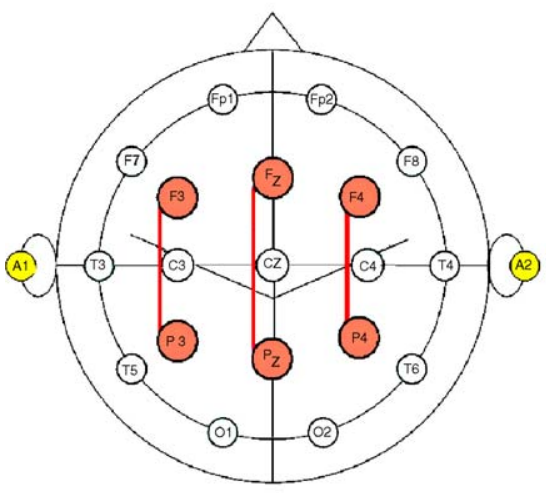

FRONTO-PARIETAL

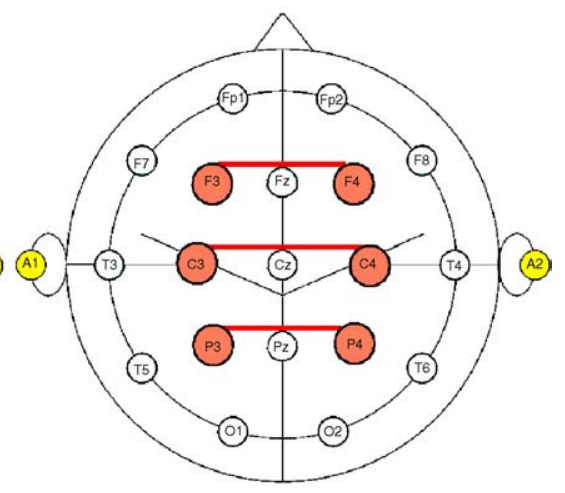

INTER-HEMISPHERICAL

Fig. 1. Fronto-parietal (F3-P3, Fz-Pz, F4-P4) and the inter-hemispheric (F3-F4, C3-C4, P3-P4) pairs of electrodes at which synchronization likelihood was computed from Laplacian-transformed resting EEG data. Electrodes positioned according to the International 10-20 System. 


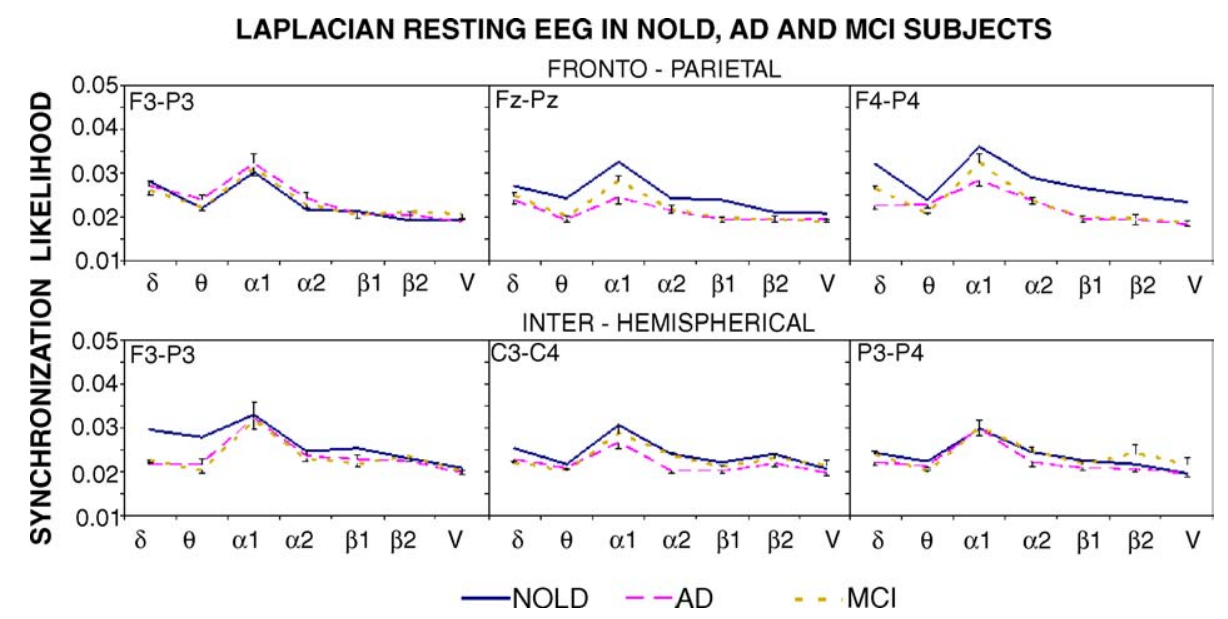

Fig. 2. Means of the synchronization likelihood computed in Nold (blue), mild AD (red), and MCI (yellow) subjects from fronto-parietal (F3-P3, Fz-Pz, F4-P4) and inter-hemispheric (F3-F4, C3-C4, P3-P4) electrode pairs. Frequency bands of interest were delta, theta, alpha 1, alpha 2, beta 1, beta 2, and gamma. (For interpretation of the references to colour in this figure legend, the reader is referred to the web version of the article.)

hemispheric (bottom of the figure: F3-F4, C3-C4, P3-P4) electrode pairs at all frequency bands of interest (delta, theta, alpha 1 , alpha 2 , beta 1 , beta 2 , gamma). Compared to Nold subjects, both MCI and mild AD subjects had lower synchronization likelihood values. This was true at both fronto-parietal (especially at delta and alpha rhythms) and inter-hemispheric (especially at frontal delta and theta rhythms) electrode pairs. Of note, the synchronization likelihood values were generally lower also in mild AD than in MCI subjects.

Statistical ANOVA analysis of the synchronization likelihood for the fronto-parietal coupling showed a significant interaction $(F(24,3156)=1.95 ; p<0.003)$ among the factors Aging group (Nold, mild AD, MCI), Fronto-parietal electrode pair (F3-P3, Fz-Pz, F4-P4), and Frequency band of interest (delta, theta, alpha 1, alpha 2, beta 1, beta 2, gamma). Duncan post hoc testing showed that synchronization likelihood values matched the pattern Nold > MCI > AD at delta and alpha $1(p<0.05)$. At delta, this was true for right Fronto-parietal electrode pair (F4-P4; $p<0.006$ to $p<7 \times 10^{-6}$ Nold $>\mathrm{MCI}>\mathrm{AD}$ ). At alpha 1 , this was true for midline Fronto-parietal electrode pair $(\mathrm{Fz}-\mathrm{Pz}$; $p<0.001-0.006$ Nold $>\mathrm{MCI}>\mathrm{AD})$ and right Fronto-parietal electrode pair (F4-P4; $p<0.003-0.002$ Nold $>\mathrm{MCI}>\mathrm{AD}$ ).

Correlation of the aforementioned significant synchronization likelihood values $(p<0.05)$ with MMSE scores was performed in all subjects as whole group. Bonferroni correction was applied for three repetitions of the Pearson test $(p<0.05$ corrected $=p<0.016)$. There was a positive correlation between synchronization likelihood and MMSE score at delta for right Fronto-parietal electrode pair (F4-P4; $r=0.23$, $p=10^{-4}$ ), at alpha 1 for midline electrode pair (Fz-Pz; $r=0.23$, $\left.p=2 \times 10^{-4}\right)$, and right Fronto-parietal electrode pair (F4-P4; $\left.r=0.20, p=9 \times 10^{-4}\right)$. Fig. 3 shows the two relative scatter plots.

Table 2 reports the coefficient of the $r^{2}$ determination between synchronization likelihood and the MMSE score in all subjects considered as a whole group. The $r^{2}$ value is reported for linear, exponential, logarithmic, and power functions. In general, $r^{2}$ values for linear, exponential, logarithmic, and power functions were quite similar. No clear predominance of non-linear or linear values was observed.

Statistical ANOVA analysis of the synchronization likelihood for inter-hemispheric coupling showed no significant interaction among the factors Aging group (Nold, mild AD, MCI), Inter-hemispheric electrode pair (F3-F43, C3-C4, P3-P4), and Frequency band of interest (delta, theta, alpha 1, alpha 2, beta 1 , beta 2, gamma). It is probable that the clear difference of delta and theta synchronization likelihood among groups was insufficient to render statistically significant such an ANOVA interaction.

\subsection{Control analysis}

Since age, education, and gender significantly differed among Nold, MCI, and mild AD subjects, a control ANOVA analysis was necessary to assure that the EEG differences among the three groups were not due to the mentioned personal parameters. We

Table 2

Correlation (coefficient of determination $r^{2}$ ) between synchronization likelihood (LORETA current density) and the MMSE score in all subjects considered as a single group

\begin{tabular}{lllll}
\hline & \multicolumn{3}{l}{$r^{2}$ coefficient between LORETA current density and MMSE } & \\
\cline { 2 - 5 } & Linear & Logarithmic & Exponential & Power \\
\hline Delta F4-P4 & 0.0544 & 0.0496 & 0.039 & 0.0352 \\
Alpha 1 Fz-Pz & 0.0508 & 0.0482 & 0.0692 & 0.0668 \\
Alpha 1 F4-P4 & 0.0409 & 0.0407 & 0.0499 & 0.049 \\
\hline
\end{tabular}

The $r^{2}$ value is reported for linear, exponential, logarithmic, and power function. 

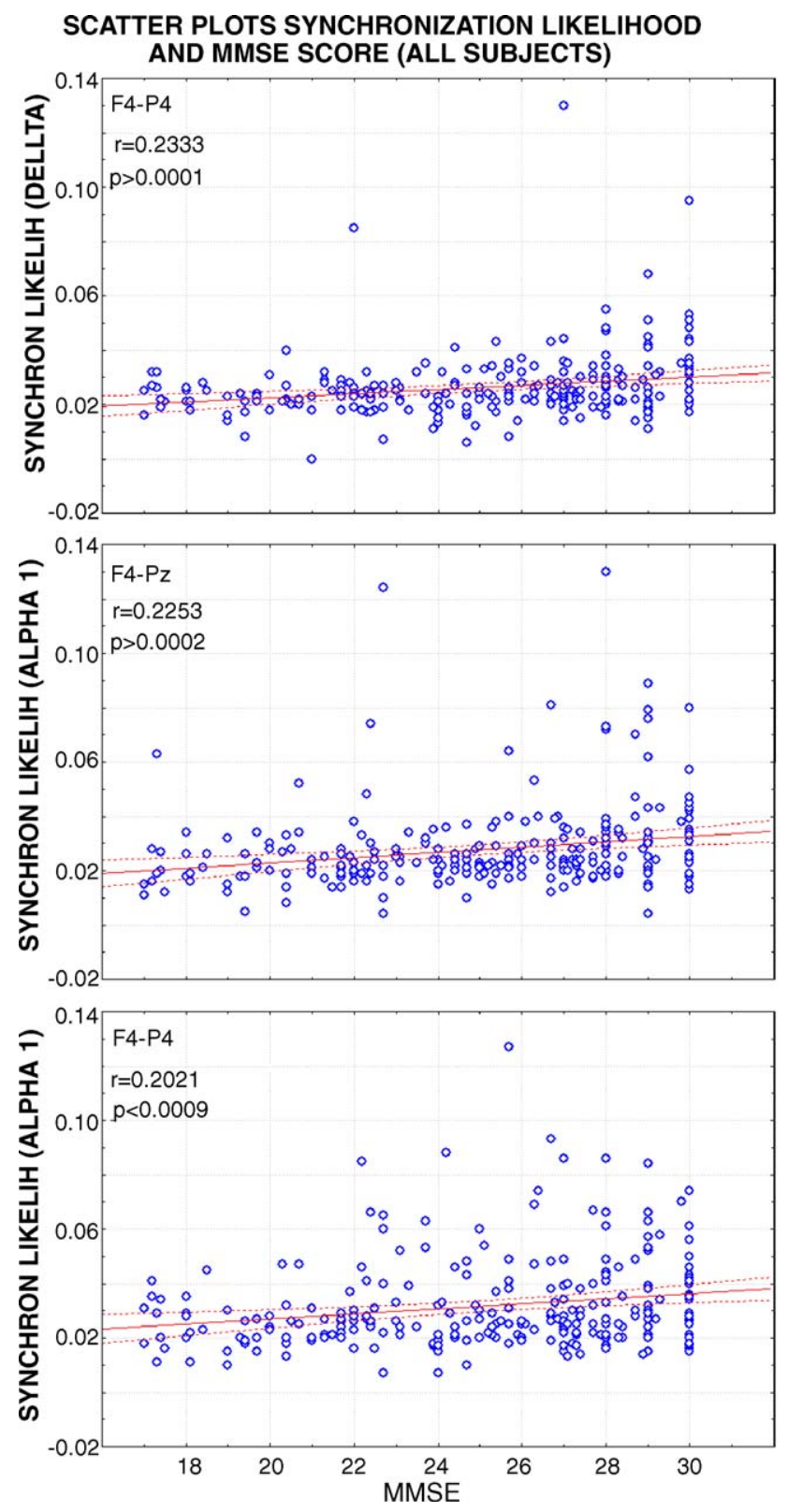

Fig. 3. Scatter plots between individual values of synchronization likelihood and mini mental state evaluation (MMSE) scores at delta band for the electrode pair F4-P4 and at alpha 1 band for the electrode pairs Fz-Pz and F4-P4. At these electrode pairs the amplitude of synchronization likelihood statistically distinguished Nold from MCI subjects and MCI from mild AD subjects.

considered sub-groups of Nold $(N=48), \mathrm{MCI}(N=48)$, and mild $\mathrm{AD}(N=48)$ subjects, having practically equal age (Nold $=72.2$, $\mathrm{AD}=72.8, \mathrm{MCI}=71.8$ years), education ( 7.9 years), and ratios of gender $(50 \%)$. MMSE score of these three sub-groups were as similar as that of the whole sample. Statistical ANOVA analysis of the synchronization likelihood for the fronto-parietal electrodes showed a significant interaction $(F(24,1704)=1.54$; $p=0.046$ ) among the factors Aging group (Nold, mild AD, MCI), Fronto-parietal electrode pair (F3-P3, Fz-Pz, F4-P4), and Frequency band of interest (delta, theta, alpha 1, alpha 2, beta 1 , beta 2 , gamma). This control ANOVA analysis fully confirmed the results obtained with the larger groups. Fig. 4 showed profile and magnitude of these results in Nold, MCI, and mild AD sub-groups were similar compared to those of the larger three groups with age, education and gender bias. Compared to Nold subjects, both MCI and mild AD subjects had lower synchronization likelihood values. Therefore, it was unlikely that the synchronization likelihood differences obtained in the full groups were due to age, education, and gender.

\section{Discussion}

A crucial issue of the present study was whether frontoparietal coupling of resting EEG rhythms was sensitive to the shadow region between MCI and AD conditions, in line with the hypothesis that MCI can be considered as a pre-clinical stage of the disease at group level. The results showed that delta and alpha synchronization likelihood at fronto-parietal electrode pairs correlated with the global cognitive status (MMSE score) in all subjects and permitted to statistically distinguish MCI group from Nold and mild AD groups. These results extend previous evidence showing that fronto-parietal alpha synchronization likelihood had similar magnitude in mild $\mathrm{AD}$ and vascular dementia patients with comparable levels of cognitive impairment; whereas, the magnitude of the inter-hemispheric alpha synchronization likelihood decreased much less in mild $A D$ than in vascular dementia patients [10]. Furthermore, they are in agreement with previous findings showing that global synchronization likelihood of resting alpha rhythms (each channel versus all others) was significantly decreased in $\mathrm{AD}$ patients, when compared to MCI and/or Nold subjects [85,105]. Finally, they complement previous magnetoencephalographic findings in $\mathrm{AD}$ patients disclosing a reduction of the alpha synchronization likelihood when compared to normative data [104,105].

The present results showed an apparent paradox. Why did the synchronization likelihood at fronto-parietal and frontal interhemispheric electrodes decrease rather than increase in MCI and AD subjects when compared to Nold subjects? Indeed, power of resting delta rhythms is typically higher in $\mathrm{MCI}$ and $\mathrm{AD}$ patients than in Nold subjects [6,7]. The answer requires a slight change of perspective on resting delta rhythms. They would not be just a reflection of pathological synchronization mechanisms in wake neurological subjects. Rather, delta rhythms would be present in wake normal subjects as an underground pattern of synchronization connecting frontal and parietal neural networks. They could sub-serve homeostatic pressure towards sleep, in line with previous evidence showing that in normal subjects, diurnal delta rhythms increase in magnitude as a function of the time period from last sleep episode $[61,70]$. In this theoretical framework, neurodegenerative aging processes could enhance the power of local delta rhythms and disrupt the normal coordination of these rhythms in frontal and parietal areas.

When compared to fronto-parietal synchronization likelihood, inter-hemispheric synchronization likelihood was less effective to set apart MCI from normal and mild AD subjects. As aforementioned, the only exception was represented by the frontal inter-hemispheric synchronization likelihood at slow rhythms (delta and theta). It was lower in magnitude in $\mathrm{AD}$ patients than in MCI and Nold subjects. These findings are 

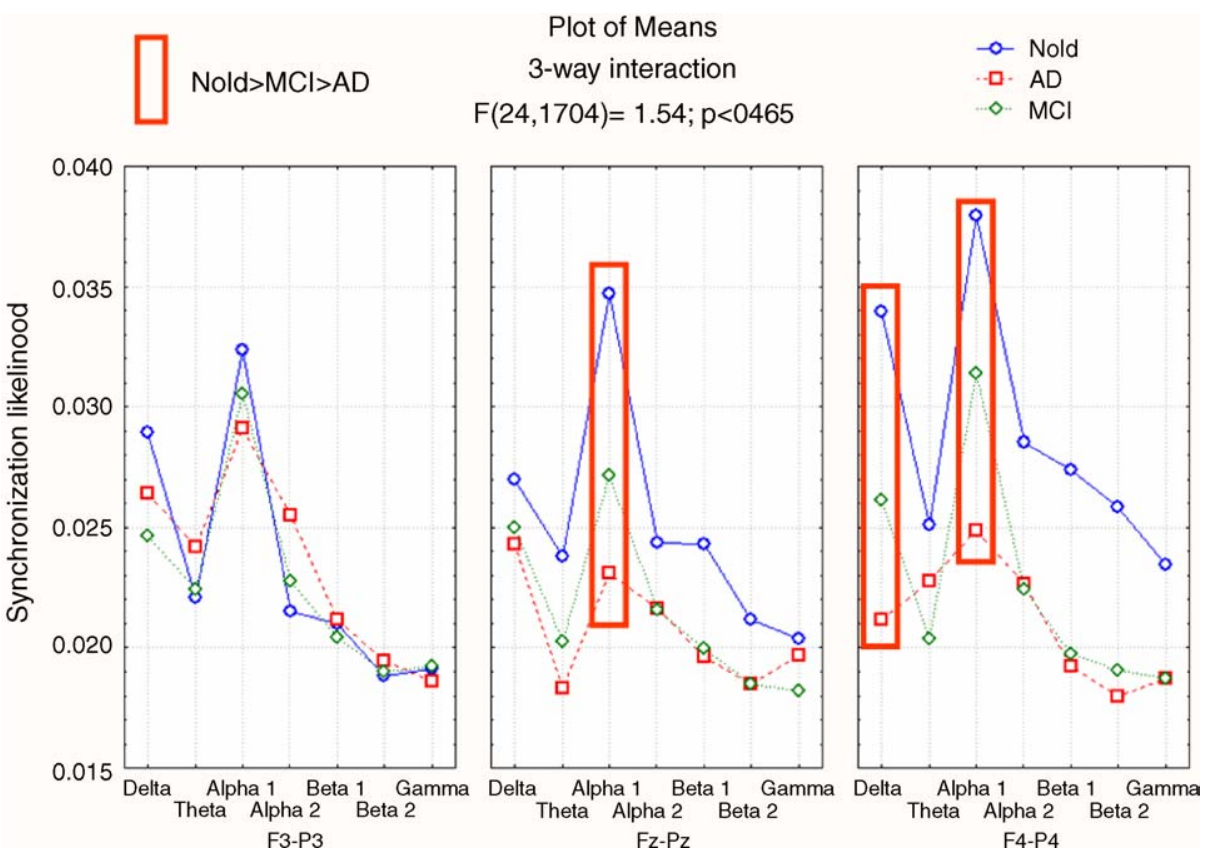

Fig. 4. Means of the synchronization likelihood computed in Nold (blue), mild AD (red), and MCI (yellow) subjects from fronto-parietal (F3-P3, Fz-Pz, F4-P4) electrode pairs, relative to a statistical ANOVA analysis of the synchronization likelihood for the fronto-parietal coupling that showed a significant interaction $(F(24,1704)=1.54 ; p=0.046)$ among the factors Aging group (Nold, mild AD, MCI), Fronto-parietal electrode pair (F3-P3, Fz-Pz, F4-P4), and Frequency band of interest (delta, theta, alpha 1, alpha 2, beta 1, beta 2, gamma). This control ANOVA analysis fully confirmed the results obtained with the larger groups. Duncan post hoc testing showed that synchronization likelihood values matched the pattern Nold $>$ MCI $>$ AD at delta and alpha $1(p<0.05)$. The rectangles indicate the cortical regions and frequency bands in which synchronization likelihood presented statistically significant different values with respect to the patterns: Nold $>$ MCI $>$ mild AD. (For interpretation of the references to colour in this figure legend, the reader is referred to the web version of the article.)

in accordance with preceding evidence on the functional effects of atrophy of corpus callosum $[60,70,86,87,111,117]$. They are also in accordance with preceding evidence on the reduction of the inter-hemispheric coupling at slow rhythms in physiological and pathological aging [1,53,114].

In the present study, the decrease of the delta and alpha synchronization likelihood was preponderant at the right frontoparietal leads in both MCI and AD subjects. However, no definitive conclusion can be drawn about that functional hemispheric asymmetry. Previous AD studies have shown the high variability of EEG results in this respect. It has been reported that the decrement of the delta coherence was maximum at the right hemisphere [79] or at the left hemisphere [67]. Other studies have pointed to a more complex hemispheric pattern of delta and alpha coherence $[22,23]$. Of note, the present results could not be compared to previous evidence showing decreased theta coherence at left temporal electrodes in AD patients [1]. Indeed, the surface Laplacian estimation is not reliable at these electrodes.

Keeping in mind our synchronization likelihood findings, fronto-parietal coupling at low-band alpha rhythms seems to be the most sensitive index of the progression from normality to $\mathrm{MCI}$ and $\mathrm{AD}$. Alpha rhythms are mainly modulated by thalamo-cortical and cortico-cortical systems $[19,84,107]$. Within extended alpha band $(8-13 \mathrm{~Hz})$, low-band alpha would be mainly related to a subject's global attentional readiness, whereas high-band alpha would reflect the engagement of specific neural channels for the elaboration of sensorimotor or semantic information [56-58]. In this theoretical frame- work, synchronization likelihood of low-band alpha suggests a progressive (maybe cholinergic) impairment from MCI to mild $\mathrm{AD}$ of the attentional fronto-parietal systems rather than inter-hemispherical coordination of the synchronization pattern. This explanation is in line with well-known clinical findings of increasing visual and spatial deficits in MCI and mild $\mathrm{AD}[2,115]$, the role of cholinergic systems in attention $[16,18,24,26,31]$, and the fact that cholinergic antagonist (scopolamine) reduced inter-hemispheric EEG coherences in normal subjects [54]. A reduced fronto-parietal coupling at low-band alpha rhythm would reflect not simply the loss of long distance axons but also the (cholinergic) basal forebrain projections to the cortex and hippocampus $[55,69]$. This would have crucial effects on the cognition, which can be conceptualized as a dynamic process that requires the constant modification of different synchronized neural networks [17,33,37-39,71]. This process would be reflected in spontaneous fluctuations in the mean level of synchronization of neural networks. Recent evidence is in favor of the idea that these spontaneous fluctuations (including those at low-band alpha) are reduced in AD [63].

\section{Conclusions}

It has been previously shown that fronto-parietal coupling of resting EEG data, as revealed by synchronization likelihood, distinguishes mild $\mathrm{AD}$ patients with respect to Nold and vascular dementia subjects [10]. Here, we tested whether fronto-parietal EEG synchronization likelihood progressively becomes abnormal through MCI and mild AD conditions, in line with the 
hypothesis that MCI can be considered as a pre-clinical stage of the disease at group level. An original contribution of this study was to combine two major methodological aspects: (i) it extended the evaluation of the cortical functional coupling to large groups of MCI and mild AD subjects and (ii) focused on its spatial detail. Results showed that delta and alpha synchronization likelihood at fronto-parietal rather than inter-hemispherical electrode pairs progressively decreased through MCI and mild AD groups. As a further sign of specificity, the fronto-parietal synchronization likelihood at delta and alpha correlated with global cognitive status (MMSE score) across all subjects. These results suggest that the fronto-parietal coupling of EEG rhythms is quite sensitive to the pre-clinical stage of the $\mathrm{AD}$ at group level. Future longitudinal studies should ascertain whether the present EEG analysis at group level will be able to predict which individual MCI subjects will decline and develop dementia.

\section{Acknowledgments}

We thank Mrs. Gabriella Busonero, Dr. Paola Chiovenda, Dr. Claudio Del Percio, Mrs. Rita Fini, Dr. Massimo Gennarelli, Dr. Nicola Girtler, Dr. Katiuscia Sosta and Dr. Franca Tecchio for their precious help in the development of the present study. We thank also Prof. Fabrizio Eusebi for his continuous support. Dr. Fabrizio Vecchio and Dr. Andrea Cassarino participated to this study in the framework of their Ph.D. program at the Doctoral School in Neurophysiology, University of Rome "La Sapienza".

\section{References}

[1] G. Adler, S. Brassen, A. Jajcevic, EEG coherence in Alzheimer's dementia, J. Neural Transm. 110 (2003) 1051-1058.

[2] E. Arnaiz, O. Almkvist, Neuropsychological features of mild cognitive impairment and preclinical Alzheimer's disease, Acta Neurol. Scand. Suppl. 179 (2003) 34-41.

[3] J. Arnhold, P. Grassberger, K. Lehnertz, C.E. Elger, A robust method for detecting interdependencies: application to intracranially recorded EEG, Physica D 134 (1999) 419-430.

[4] C. Babiloni, F. Babiloni, F. Carducci, F. Cincotti, F. Rosciarelli, P. Rossini, L. Arendt-Nielsen, A. Chen, Mapping of early and late human somatosensory evoked brain potentials to phasic galvanic painful stimulation, Hum. Brain Mapp. 12 (2001) 168-179.

[5] F. Babiloni, C. Babiloni, F. Carducci, L. Fattorini, P. Onorati, A. Urbano, Spline Laplacian estimate of EEG potentials over a realistic magnetic resonance-constructed scalp surface model, Electroencephalogr. Clin. Neurophysiol. 98 (1996) 363-373.

[6] C. Babiloni, G. Binetti, A. Cassarino, G. Dal Forno, C. Del Percio, F. Ferreri, R. Ferri, G. Frisoni, S. Galderisi, K. Hirata, B. Lanuzza, C. Miniussi, A. Mucci, F. Nobili, G. Rodriguez, G.L. Romani, P.M. Rossini, Sources of cortical rhythms in adults during physiological aging: a multi-centric EEG study. Hum. Brain Mapp. (2005) (Epub ahead of print).

[7] C. Babiloni, G. Binetti, E. Cassetta, D. Cerboneschi, G. Dal Forno, C. Del Percio, F. Ferreri, R. Ferri, B. Lanuzza, C. Miniussi, D.V. Moretti, F. Nobili, R.D. Pascual-Marqui, G. Rodriguez, G.L. Romani, S. Salinari, F. Tecchio, P. Vitali, O. Zanetti, F. Zappasodi, P.M. Rossini, Mapping distributed sources of cortical rhythms in mild Alzheimers disease. A multi-centric EEG study, NeuroImage 22 (2004) 57-67.

[8] F. Babiloni, F. Carducci, C. Babiloni, A. Urbano, Improved realistic Laplacian estimate of highly-sampled EEG potentials by regularization techniques, Electroencephalogr. Clin. Neurophysiol. 106 (1998) 336-343.
[9] F. Babiloni, F. Carducci, F. Cincotti, C. Del Gratta, V. Pizzella, G.L. Romani, P.M. Rossini, F. Tecchio, C. Babiloni, Linear inverse source estimate of combined EEG and MEG data related to voluntary movements, Hum. Brain Mapp. 14 (2001) 197-209.

[10] C. Babiloni, R. Ferri, D.V. Moretti, A. Strambi, G. Binetti, G. Dal Forno, F. Ferreri, B. Lanuzza, C. Bonato, F. Nobili, G. Rodriguez, S. Salinari, S. Passero, R. Rocchi, C.J. Stam, P.M. Rossini, Abnormal fronto-parietal coupling of brain rhythms in mild Alzheimer's disease: a multicentric EEG study, Eur. J. Neurosci. 19 (2004) 2583-2590.

[11] D.L. Bachman, P.A. Wolf, R.T. Linn, J.E. Knoefel, J.L. Cobb, A.J. Belanger, L.R. White, R.B. D'Agostino, Incidence of dementia and probable Alzheimer's disease in a general population: the Framingham Study, Neurology 43 (1993) 515-519.

[12] H.W. Berendse, J.P. Verbunt, P. Scheltens, B.W. Dijk, E.J. van, E.J. Jonkman, Magnetoencephalographic analysis of cortical activity in Alzheimer's disease. A pilot study, Clin. Neurophysiol. 111 (2000) 604-612.

[13] C. Besthorn, H. Forstl, C. Geiger-Kabisch, H. Sattel, T. Gasser, U. Schreiter-Gasser, EEG coherence in Alzheimer disease, Electroencephalogr. Clin. Neurophysiol. 90 (1994) 242-245.

[14] C. Besthorn, R. Zerfass, C. Geiger-Kabisch, H. Sattel, S. Daniel, U. Schreiter-Gasser, H. Forstl, Discrimination of Alzheimer's disease and normal aging by EEG data, Electroencephalogr. Clin. Neurophysiol. 103 (1997) 241-248.

[15] H. Braak, E. Braak, Demonstration of amyloid deposits and neurofibrillary changes in whole brain sections, Brain Pathol. 1 (1991) 213-216.

[16] D. Brandeis, H. Naylor, R. Halliday, E. Callaway, L. Yano, Scopolamine effects on visual information processing, attention, and eventrelated potential map latencies, Psychophysiology 29 (1992) 315-336.

[17] M. Breakspear, Nonlinear phase desynchronization in human electroencephalographic data, Hum. Brain Mapp. 15 (2002) 175-198.

[18] P. Broks, G.C. Preston, M. Traub, P. Poppleton, C. Ward, S.M. Stahl, Modelling dementia: effects of scopolamine on memory and attention, Neuropsychology 26 (1988) 685-700.

[19] C.H. Brunia, Neural aspects of anticipatory behavior, Acta Psychol. 101 (1999) 213-242.

[20] M. Brunovsky, M. Matousek, A. Edman, K. Cervena, V. Krajca, Objective assessment of the degree of dementia by means of EEG, Neuropsychobiology 48 (2003) 19-26.

[21] R.J. Buchan, K. Nagata, E. Yokoyama, P. Langman, H. Yuya, Y. Hirata, J. Hatazawa, I. Kanno, Regional correlations between the EEG and oxygen metabolism in dementia of Alzheimer's type, Electroencephalogr. Clin. Neurophysiol. 103 (1997) 409-417.

[22] P.L. Calderon, M. Parra, J.J. Llibre, A.E. Fernandez, E.M. Gongora, The role of the cerebral coherence in the progress of the patient with Alzheimer's disease, Rev. Neurol. 25 (1997) 1393-1398.

[23] P.L. Calderon, M.A. Parra Rodriguez, J.J. Llibre Rodriguez, J.V. Gutierrez, Spectral analysis of EEG coherence in Alzheimer's disease, Rev. Neurol. 38 (2004) 422-427.

[24] M.J. Callahan, J.J. Kinsora, R.E. Harbaugh, T.M. Reeder, R.E. Davis, Continuous ICV infusion of scopolamine impairs sustained attention of rhesus monkeys, Neurobiol. Aging 14 (1993) 147-151.

[25] P. Celsis, A. Agniel, M. Puel, A. Le Tinnier, G. Viallard, J.F. Demonet, A. Rascol, J.P. Marc-Vergnes, Lateral asymmetries in primary degenerative dementia of the Alzheimer type. A correlative study of cognitive, haemodynamic and EEG data, in relation with severity, age of onset and sex, Cortex 26 (1990) 585-596.

[26] M.L. Cheal, Scopolamine disrupts maintenance of attention rather than memory processes, Behav. Neural. Biol. 33 (1981) 163-187.

[27] R. Chiaramonti, G.C. Muscas, M. Paganini, T.J. Muller, A.J. Fallgatter, A. Versari, W.K. Strik, Correlations of topographical EEG features with clinical severity in mild and moderate dementia of Alzheimer type, Neuropsychobiology 36 (1997) 153-158.

[28] T. Dierks, R. Ihl, L. Frolich, K. Maurer, Dementia of the Alzheimer type: effects on the spontaneous EEG described by dipole sources, Psychiatry Res. 50 (1993) 151-162.

[29] T. Dierks, V. Jelic, R.D. Pascual-Marqui, L. Wahlund, P. Julin, D.E. Linden, K. Maurer, B. Winblad, A. Nordberg, Spatial pattern of cere- 
bral glucose metabolism (PET) correlates with localization of intracerebral EEG-generators in Alzheimer's disease, Clin. Neurophysiol. 111 (2000) 1817-1824.

[30] J.J. Dunkin, A.F. Leuchter, T.F. Newton, I.A. Cook, Reduced EEG coherence in dementia: state or trait marker? Biol. Psychiatry 35 (1994) 870-879.

[31] M.P. Dunne, L.R. Hartley, Scopolamine and the control of attention in humans, Psychopharmacology (Berl.) 89 (1986) 94-97.

[32] S. Elmstahl, I. Rosen, Postural hypotension and EEG variables predict cognitive decline: results from a 5-year follow-up of healthy elderly women, Dement. Geriatr. Cogn. Disord. 8 (1997) 180-187.

[33] W.J. Feeman, L.J. Rogers, Fine temporal resolution of analytic phase reveals episodic synchronization by state transitions in gamma EEGs, J. Neurophysiol. 87 (2002) 937-945.

[34] C. Flicker, S.H. Ferris, B. Reisberg, Mild cognitive impairment in the elderly: predictors of dementia, Neurology 41 (1991) 1006-1009.

[35] M.F. Folstein, S.E. Folstein, P.R. McHugh, 'Mini Mental State': a practical method for grading the cognitive state of patients for clinician, J. Psychiatry Res. 12 (1975) 189-198.

[36] G.B. Frisoni, A. Padovani, L.O. Wahlund, The predementia diagnosis of Alzheimer disease, Alzheimer Dis. Assoc. Disord. 18 (2004) 51-53.

[37] K.J. Friston, The labile brain. I. Neuronal transients and nonlinear coupling, Philos. Trans. R. Soc. Lond. B Biol. Sci. 355 (2000) 215-236.

[38] K.J. Friston, The labile brain. II. Transients, complexity and selection, Philos. Trans. R. Soc. Lond. B Biol. Sci. 355 (2000) 237-252.

[39] K.J. Friston, The labile brain. III. Transients and spatio-temporal receptive fields, Philos. Trans. R. Soc. Lond. B Biol. Sci. 355 (2000) 253-265.

[40] T. Frodl, H. Hampel, G. Juckel, K. Burger, F. Padberg, R.R. Engel, H.J. Moller, U. Hegerl, Value of event-related P300 subcomponents in the clinical diagnosis of mild cognitive impairment and Alzheimer's disease, Psychophysiology 39 (2002) 175-181.

[41] S. Galluzzi, L. Cimaschi, L. Ferrucci, G.B. Frisoni, Mild cognitive impairment: clinical features and review of screening instruments, Aging (Milano) 13 (2001) 183-202.

[42] S. Gao, H.C. Hendrie, K.S. Hall, S. Hui, The relationships between age, sex, and the incidence of dementia and Alzheimer disease: a meta-analysis, Arch. Gen. Psychiatry 55 (1998) 809-815.

[43] M. Grunwald, F. Busse, A. Hensel, F. Kruggel, S. Riedel-Heller, H. Wolf, T. Arendt, H.J. Gertz, Related Articles, Links correlation between cortical theta activity and hippocampal volumes in health, mild cognitive impairment, and mild dementia, J. Clin. Neurophysiol. 18 (2001) 178-184.

[44] M. Grunwald, F. Busse, A. Hensel, S. Riedel-Heller, F. Kruggel, T. Arendt, H. Wolf, H.J. Gertz, Theta-power differences in patients with mild cognitive impairment under rest condition and during haptic tasks, Alzheimer Dis. Assoc. Disord. 16 (2002) 40-48.

[45] C. Huang, L. Wahlund, T. Dierks, P. Julin, B. Winblad, V. Jelic, Discrimination of Alzheimer's disease and mild cognitive impairment by equivalent EEG sources: a cross-sectional and longitudinal study, Clin. Neurophysiol. 111 (2000) 1961-1967.

[46] C.P. Hughes, L. Berg, W.L. Danziger, L.A. Cohen, R.L. Martin, A new clinical rating scale for the staging of dementia, Br. J. Psychiatry 140 (1982) 1225-1230.

[47] R. Ihl, C. Eilles, L. Frlich, K. Maurer, T. Dierks, I. Perisic, Electrical brain activity and cerebral blood flow in dementia of the Alzheimer type, Psychiatry Res. 29 (1989) 449-452.

[48] V. Jelic, S.E. Johansson, O. Almkvist, M. Shigeta, P. Julin, A. Nordberg, B. Winblad, L.O. Wahlund, Quantitative electroencephalography in mild cognitive impairment: longitudinal changes and possible prediction of Alzheimer's disease, Neurobiol. Aging 21 (2000) 533 540.

[49] V. Jelic, P. Julin, M. Shigeta, A. Nordberg, L. Lannfelt, B. Winblad, L.O. Wahlund, Apolipoprotein, E epsilon4 allele decreases functional connectivity in Alzheimer's disease as measured by EEG coherence, J. Neurol. Neurosurg. Psychiatry 63 (1997) 59-65.

[50] V. Jelic, M. Shigeta, P. Julin, O. Almkvist, B. Winblad, L.O. Whalund, Quantitative electroencephalography power and coherence in Alzheimer's disease and mild cognitive impairment, Dementia 7 (1996) 314-323.

[51] G. Johannesson, A. Brun, I. Gustafson, D.H. Ingvar, EEG in presenile dementia related to cerebral blood flow and autopsy findings, Acta Neurol. Scand. 56 (1977) 89-103.

[52] P. Julin, L.O. Wahlund, H. Basun, A. Persson, K. Mare, U. Rudberg, Clinical diagnosis of frontal lobe dementia and Alzheimer's disease: relation to cerebral perfusion, brain atrophy and electroencephalography, Dementia 6 (1995) 142-147.

[53] M. Kikuchi, Y. Wada, Y. Koshino, Y. Nanbu, T. Hashimoto, Effect of normal aging upon interhemispheric EEG coherence: analysis during rest and photic stimulation, Clin. Electroencephalogr. 31 (2000) 170-174.

[54] M. Kikuchi, Y. Wada, Y. Koshino, Y. Nanbu, T. Hashimoto, Effects of scopolamine on interhemispheric EEG coherence in healthy subjects: analysis during rest and photic stimulation, Clin. Electroencephalogr. 31 (2000) 109-115.

[55] S. Kleiner, A. Bringmann, Nucleus basalis magnocellularis and pedunculopontine tegmental nucleus: control of the slow EEG waves in rats, Arch. Ital. Biol. 134 (1996) 153-167.

[56] W. Klimesch, Memory processes, brain oscillations and EEG synchronization, Int. J. Psychophysiol. 24 (1996) 61-100.

[57] W. Klimesch, M. Doppelmayr, T. Pachinger, H. Russegger, Eventrelated desynchronization in the alpha band and the processing of semantic information, Brain Res. Cogn. Brain Res. 6 (1997) 83-94.

[58] W. Klimesch, M. Doppelmayr, H. Russegger, T. Pachinger, J. Schwaiger, Induced alpha band power changes in the human EEG and attention, Neurosci. Lett. 244 (1998) 73-76.

[59] V. Knott, E. Mohr, C. Mahoney, V. Ilivitsky, Electroencephalographic coherence in Alzheimer's disease: comparisons with a control group and population norms, J. Geriatr. Psychiatry Neurol. 13 (2000) 1-8.

[60] M.G. Knyazeva, G.M. Innocenti, EEG coherence studies in the normal brain and after early-onset cortical pathologies, Brain Res. Brain Res. Rev. 36 (2001) 119-128.

[61] C. Lafrance, J. Paquet, M. Dumont, Diurnal time courses in psychomotor performance and waking EEG frequencies, Brain Cogn. 48 (2002) 625-631.

[62] M.P. Lawton, E.M. Brodie, Assessment of older people: self maintaining and instrumental activity of daily living, J. Gerontol. 9 (1969) 179-186.

[63] A.F. Leuchter, I.A. Cook, T.F. Newton, J. Dunkin, D.O. Walter, S. Rosenberg-Thompson, P.A. Lachenbruch, H. Weiner, Regional differences in brain electrical activity in dementia: use of spectral power and spectral ratio measures, Electroencephalogr. Clin. Neurophysiol. 87 (1993) 385-393.

[64] A.F. Leuchter, T.F. Newton, A.A. Cook, D.O. Walter, Changes in brain functional connectivity in Alzheimer-type and multi-infarct dementia, Brain 115 (1992) 1543-1561.

[65] A.F. Leuchter, J.E. Spar, D.O. Walter, H. Weiner, Electroencephalographic spectra and coherence in the diagnosis of Alzheimer's-type and multi-infarct dementia. A pilot study, Arch. Gen. Psychiatry 44 (1987) 993-998.

[66] M. Le Van Quyen, C. Adam, M. Baulac, J. Martinerie, F.J. Varela, Nonlinear interdependencies of EEG signals in human intracranially recorded temporal lobe seizures, Brain Res. 792 (1998) 24-40.

[67] T. Locatelli, M. Cursi, D. Liberati, M. Francheschi, G. Comi, EEG coherence in Alzheimer's disease, Electroencephalogr. Clin. Neurophysiol. 106 (1998) 229-237.

[68] G. McKahn, D. Drachman, M. Folstein, R. Katzman, D. Price, E.M. Stadlan, Clinical diagnosis of Alzheimer's disease: report of the NINCDS-ADRDA Work Group under the auspices of Department of Health and Human Services Task Force on Alzheimer's Disease, Neurology 34 (1984) 939-944.

[69] M. Mesulam, The cholinergic lesion of Alzheimer's disease: pivotal factor or side show? Learn. Mem. 11 (2004) 43-49.

[70] J. Montplaisir, T. Nielsen, J. Cote, D. Boivin, I. Rouleau, G. Lapierre, Interhemispheric EEG coherence before and after partial callosotomy, Clin. Electroencephalogr. 21 (1990) 42-47. 
[71] D.V. Moretti, C. Babiloni, G. Binetti, E. Cassetta, G. Dal Forno, F. Ferreri, R. Ferri, B. Lanuzza, C. Miniussi, F. Nobili, G. Rodriguez, S. Salinari, P.M. Rossini, Individual analysis of EEG frequency and band power in mild Alzheimer's disease, Clin. Neurophysiol. 115 (2004) 299-308.

[72] D.V. Moretti, F. Babiloni, F. Carducci, F. Cincotti, E. Remondini, P.M. Rossini, S. Salinari, C. Babiloni, Computerized processing of EEG-EOG-EMG artifacts for multicentirc studies in EEG oscillations and event-related potentials, Int. J. Pshycophysiol. 47 (2003) 199-216.

[73] T.J. Muller, J. Thome, R. Chiaramonti, T. Dierks, K. Maurer, A.J. Fallgatter, L. Frolich, M. Scheubeck, W.K. Strik, A comparison of qEEG and HMPAO-SPECT in relation to the clinical severity of Alzheimer's disease, Eur. Arch. Psychiatry Clin. Neurosci. 247 (1997) 259-263.

[74] F. Nobili, M. Koulibaly, P. Vitali, O. Migneco, G. Mariani, K. Ebmeier, A. Pupi, P.H. Robert, G. Rodriguez, J. Darcourt, Brain perfusion follow-up in Alzheimer's patients during treatment with acetylcholinesterase inhibitors, J. Nucl. Med. 43 (2002) 983-990.

[75] F. Nobili, P. Vitali, M. Canfora, N. Girtler, C. De Leo, G. Mariani, A. Pupi, G. Rodriguez, Effects of long-term Donepezil therapy on rCBF of Alzheimer's patients, Clin. Neurophysiol. 113 (2002) 1241-1248.

[76] P. Nunez, Neocortical Dynamics and Human EEG Rhythms, Oxford University Press, New York, 1995.

[77] P.L. Nunez, R.B. Silberstein, Z. Shi, M.R. Carpenter, R. Srinivasan, D.M. Tucker, S.M. Doran, P.J. Cadusch, R.S. Wijesinghe, EEG cohenrency II: experimental comparisons of multiple measures, Clin. Neurophysiol. 110 (1999) 469-486.

[78] P.L. Nunez, R. Srinivasan, A.F. Westdorp, R.S. Wijesinghe, D.M. Tucker, R.B. Silberstein, P.J. Cadusch, EEG coherency I: statistics, reference electrode, volume conduction, Laplacians, cortical imaging, and interpretation at multiple scales, Electroencephalogr. Clin Neurophysiol. 103 (1997) 499-515.

[79] K.P. O'Connor, J.C. Shaw, C.O. Ongley, The EEG and differential diagnosis in psychogeriatrics, Br. J. Psychiatry 135 (1979) 156-162.

[80] S. Passero, R. Rocchi, G. Vatti, L. Burgalassi, N. Battistini, Quantitative EEG mapping, regional cerebral blood flow, and neuropsychological function in Alzheimer's disease, Dementia 6 (1995) 148-156.

[81] R.C. Petersen, R. Doody, A. Kurz, R.C. Mohs, J.C. Morris, P.V. Rabins, K. Ritchie, M. Rossor, L. Thal, B. Winblad, Current concepts in mild cognitive impairment, Arch. Neurol. 58 (2001) 1985-1992.

[82] R.C. Petersen, G.E. Smith, R.J. Ivnik, E.G. Tangalos, D.J. Schaid, S.N. Thibodeau, E. Kokmen, S.C. Waring, L.T. Kurland, Apolipoprotein E status as a predictor of the development of Alzheimer's disease in memory-impaired individuals, JAMA 273 (1995) 1274-1278 (Erratum in: JAMA 274 (1995) 538).

[83] R.C. Petersen, G.E. Smith, S.C. Waring, R.J. Ivnik, E.G. Tangalos, E. Kokmen, Mild cognitive impairment: clinical characterization and outcome, Arch. Neurol. 56 (3) (1999 March) 303-308 (Erratum in: Arch. Neurol. 56 (1999) 760).

[84] G. Pfurtscheller, F. Lopez da Silva, Event-related EEG/MEG synchronization and desynchronization: basic principles, Clin. Neurophysiol. 110 (1999) 1842-1857.

[85] Y.A. Pijnenburg, Y. van der Made, A.M. van Cappellen van Walsum, D.L. Knol, P. Scheltens, C.J. Stam, EEG synchronization likelihood in mild cognitive impairment and Alzheimer's disease during a working memory task, Clin. Neurophysiol. 115 (2004) 1332-1339.

[86] H.B. Pinkofsky, F.A. Struve, M.A. Meyer, G. Patrick, R.R. Reeves, Decreased multi-band posterior interhemispheric coherence with a lipoma on the corpus callosum: a case report of a possible association, Clin. Electroencephalogr. 28 (1997) 155-159.

[87] O. Pogarell, S.J. Teipel, G. Juckel, L. Gootjes, T. Moller, K. Burger, G. Leinsinger, H.J. Moller, U. Hegerl, H. Hampel, Related Articles, Links EEG coherence reflects regional corpus callosum area in Alzheimer's disease, J. Neurol. Neurosurg. Psychiatry 76 (2005) 109-111.

[88] N.V. Ponomareva, N.D. Selesneva, G.A. Jarikov, EEG alterations in subjects at high familial risk for Alzheimer's disease, Neuropsychobiology 48 (2003) 152-159.

[89] E. Pucci, N. Belardinelli, G. Cacchio, M. Signorino, F. Angeleri, EEG power spectrum differences in early and late onset forms of Alzheimer's disease, Clin. Neurophysiol. 110 (1999) 621631.

[90] G. Rodriguez, F. Copello, F. Nobili, P. Vitali, G. Perego, F. Nobili, EEG spectral profile to stage Alzheimer's disease, Clin. Neurophysiol. 110 (1999) 1831-1837.

[91] E. Rodriguez, N. George, J.P. Lachauz, J. Martinerie, B. Renault, F.J. Varela, Perception's shadow: long distance synchronization of human brain activity, Nature 397 (1999) 430-433.

[92] G. Rodriguez, F. Nobili, F. Copello, P. Vitali, M.V. Gianelli, G. Taddei, E. Catsafados, G. Mariani, 99mTc-HMPAO regional Cerebral Blood Flow and quantitative Electroencephalography in Alzheimer's disease: a correlative study, J. Nucl. Med. 40 (1999) 522-529.

[93] G. Rodriguez, F. Nobili, G. Rocca, F. DeCarli, M.V. Gianelli, G. Rosadini, Quantitative electroencephalography and regional Cerebral Blood Flow: discriminant analysis between Alzheimer's patients and healthy controls, Dement. Geriatr. Cogn. Disord. 9 (1998) 238-274.

[94] G. Rodriguez, P. Vitali, C. De Leo, F. De Carli, N. Girtler, F. Nobili, Quantitative EEG changes in Alzheimer patients during long-term donepezil therapy, Neuropsychobiology 46 (2002) 49-56.

[95] J. Rogers, S. Webster, L.F. Lue, L. Brachova, W.H. Civin, M. Emmerling, B. Shivers, D. Walker, P. McGeer, Inflammation and Alzheimer's disease pathogenesis, Neurobiol. Aging 17 (1996) 681-686.

[96] W.G. Rosen, R.D. Terry, P.A. Fuld, R. Katzman, A. Peck, Pathological verification of ischemic score in differentiation of dementias, Ann. Neurol. 7 (1980) 486-488.

[97] P. Scheltens, N. Fox, F. Barkhof, C. De Carli, Structural magnetic resonance imaging in the practical assessment of dementia: beyond exclusion, Lancet Neurol. 1 (2002) 13-21.

[98] S.J. Schiff, P. So, T. Chang, Detecting dynamical interdependence and generalized synchrony through mutual prediction in a neural ensemble, Phys. Rev. E 54 (1996) 6708-6724.

[99] T.H. Schreiber, Interdisciplinary application of nonlinear time series methods, Phys. Rep. 308 (1999) 1-64.

[100] P.H. Sheridan, S. Sato, N. Foster, G. Bruno, C. Cox, P. Fedio, T.N. Chase, Relation of EEG alpha background to parietal lobe function in Alzheimer's disease as measured by positron emission tomography and psychometry, Neurology 38 (1988) 747-750.

[101] E.P. Sloan, G.W. Fenton, N.S.J. Kennedy, J.M. MacLennan, Electroencephalography and single photon emission computed tomography in dementia: a comparative study, Psychol. Med. 25 (1995) 631638.

[102] G.W. Small, P.V. Rabins, P.P. Barry, N.S. Buckholtz, S.T. DeKosky, S.H. Ferris, S.I. Finkel, L.P. Gwyther, Z.S. Khachaturian, B.D. Lebowitz, T.D. McRae, J.C. Morris, F. Oakley, L.S. Schneider, J.E. Streim, T. Sunderland, L.A. Teri, L.E. Tune, Diagnosis and treatment of Alzheimer disease and related disorders. Consensus statement of the American Association for Geriatric Psychiatry, the Alzheimer's Association, and the American Geriatrics Society, JAMA 278 (1997) 1363-1371.

[103] C.J. Stam, B.W. van Dijk, Synchronization likelihood: an un-biased measure of generalized synchronization in multivariate data sets, Physica D 163 (2002) 236-251.

[104] C.J. Stam, A.M. van Cappellen van Walsum, Y.A. Pijnenburg, H.W. Berendse, J.C. de Munck, P. Scheltens, B.W. van Dijk, Generalized synchronization of MEG recordings in Alzheimer's Disease: evidence for involvement of the gamma band, J. Clin. Neurophysiol. 19 (2002) $562-574$.

[105] C.J. Stam, Y. van der Made, Y.A.L. Pijnenburg, P.H. Scheltens, Synchronization of brain activity in mild cognitive impairment and early Alzheimer's disease, Acta Neurol. Scand. 108 (2003) 90-96.

[106] C.J. Stam, T. Montez, B.F. Jones, S.A. Rombouts, Y. van der Made, Y.A. Pijnenburg, P. Scheltens, Disturbed fluctuations of resting state EEG synchronization in Alzheimer's disease, Clin. Neurophysiol. 116 (2005) 708-715.

[107] M. Steriade, R.R. Llinas, The functional states of the thalamus and the associated neuronal interplay, Physiology 68 (1988) 649-742.

[108] A. Sulimov, Human scalp-recorded EEG may be a result of activity of weakly-coupled subsystems, Neurosci. Lett. 250 (1998) 72-74. 
[109] B. Szelies, M. Grond, K. Herholz, J. Kessler, T. Wullen, W.D. Heiss, Quantitative EEG mapping and PET in Alzheimer's disease, J. Neurol. Sci. 110 (1992) 46-56.

[110] F. Takens, Detecting strange attractors in turbulence, Lect. Notes Math. 898 (1981) 366-381.

[111] S.J. Teipel, H. Hampel, P. Pietrini, G.E. Alexander, B. Horwitz, E. Daley, H.J. Moller, M.B. Schapiro, S.I. Rapoport, Region-specific corpus callosum atrophy correlates with the regional pattern of cortical glucose metabolism in Alzheimer disease, Arch. Neurol. 56 (1999) 467-473.

[112] J. Theiler, Spurious dimension from correlation algorithms applied to limited time-series data, Phys. Rev. A 34 (1986) 2427-2432.

[113] Y. Wada, Y. Nanbu, M. Kikuchi, Y. Koshino, T. Hashimoto, N. Yamaguchi, Abnormal functional connectivity in Alzheimer's disease: intrahemispheric EEG coherence during rest and photic stimulation, Eur Arch. Psychiatry Clin. Neurosci. 248 (1998) 203-208.

[114] Y. Wada, Y. Nanbu, Y. Koshino, N. Yamaguchi, T. Hashimoto, Reduced interhemispheric EEG coherence in Alzheimer disease: analysis during rest and photic stimulation, Alzheimer Dis. Assoc. Dis. 12 (1998) 175-181.
[115] Q.S. Wang, J.N. Zhou, Retrieval and encoding of episodic memory in normal aging and patients with mild cognitive impairment, Brain Res. 924 (2002) 113-115.

[116] Z. Xiang, J.R. Huguenard, D.A. Prince, Cholinergic switching within neocortical inhibitory networks, Science 281 (1998) 985-988.

[117] H. Yamauchi, H. Fukuyama, K. Harada, H. Nabatame, M. Ogawa, Y. Ouchi, J. Kimura, J. Konishi, Callosal atrophy parallels decreased cortical oxygen metabolism and neuropsychological impairment in Alzheimer's disease, Arch. Neurol. 50 (1993) 1070-1074.

[118] J.A. Yesavage, T.L. Brink, T.L. Rose, O. Lum, V. Huang, M. Adey, V.O. Leirer, Development and validation of a geriatric depression screening scale: a preliminary report, J. Psychiatr. Res. 17 (1982) 37-49.

[119] R. Zappoli, A. Versari, M. Paganini, G. Arnetoli, G.C. Muscas, P.F. Gangemi, M.G. Arneodo, D. Poggiolini, F. Zappoli, A. Battaglia, Brain electrical activity (quantitative EEG and bit-mapping neurocognitive $\mathrm{CNV}$ components), psychometrics and clinical findings in presenile subjects with initial mild cognitive decline or probable Alzheimer-type dementia, Ital. J. Neurol. Sci. 16 (1995) 341-376. 